\title{
Does peri-implant bone loss affect the LL- 37 and proteinase 3 levels in peri-implant sulcus fluid?
}

\author{
Oya Turkoglu ${ }^{1 *} \mathbb{D}$, Candan Efeoglu² and Harika Atmaca $^{3}$
}

\begin{abstract}
Background: Inactive human cathelicidin antimicrobial peptide is present in neutrophils, and proteinase 3 activates this peptide by producing active LL-37 peptide. LL-37 acts as a defensive peptide in the oral tissues. In the present study, the aim was to evaluate LL-37 and proteinase 3 levels in peri-implant sulcus fluid (PISF) in implants with and without peri-implantitis.
\end{abstract}

Methods: Patients who simultaneously had dental implants with peri-implantitis and without peri-implantitis were included in the study. Forty-four samples with peri-implantitis and 34 samples without peri-implantitis from 16 patients were obtained. Intraoral evaluations such as pocket depth, modified sulcus bleeding index, and modified plaque index were noted. Enzyme-linked immunosorbent assay was used for the evaluation of PISF LL-37 and proteinase 3 levels.

Results: PISF volume was significantly increased in the implants with peri-implantitis than those without periimplantitis $(p<0.05)$. No difference was present between PISF LL-37 and proteinase 3 total amounts between the implants with and without peri-implantitis $(p>0.05)$. Pocket depths and PISF LL-37 and proteinase 3 levels were not correlated in the groups $(p>0.05)$.

Conclusions: PISF volume might be increased in response to peri-implant bone destruction. However, peri-implant tissue destruction caused by peri-implantitis does not seem to affect PISF LL-37 and proteinase 3 levels.

Keywords: Cathelicidin LL-37, Peri-implantitis, Peri-implant sulcus fluid, Proteinase 3

\section{Introduction}

Peri-implantitis is a disease affecting tissues around functional dental implants and an inflammatory condition of mucosa that is accompanied by loss of surrounding bone of the implant [1]. Dental implants are a more frequently preferred alternative for reconstruction of edentulous ridge with artificial teeth, and this inevitably leads to a higher incidence of diseases affecting the tissues around the implant. Finally, the disease might lead to implant loss. Zitzmann et al. stated that peri-

\footnotetext{
*Correspondence: oya_t@yahoo.com

'Department of Periodontology, School of Dentistry, Ege University, Bornova, 35100 Izmir, Turkey

Full list of author information is available at the end of the article
}

implantitis affects 28 and $56 \%$ of the adults and 12 and $43 \%$ of the implants [1].

Peri-implant sulcus fluid (PISF) is similar to gingival crevicular fluid as it reflects the inflammatory response $[2,3]$. It has been stated that the exudate leaking from the peri-implant tissue into the peri-implant sulcus increases during the inflammatory process [4]. Up to date, various cytokines in peri-implant sulcus fluid (PISF) have been investigated in peri-implant disease [4-7]. Matrix metalloproteinase- 8 levels were found to be higher in peri-implantitis sites [5]. Similarly, researchers have demonstrated that interleukins $1 \beta, 6$, and 10 and TNF- $\alpha$ concentrations were related to inflammatory response during peri-implantitis [6]. Acipinar et al. has demonstrated that FGF-23 and vitamin D seem to affect peri-

\section{Springer Open}

(c) The Author(s). 2020 Open Access This article is licensed under a Creative Commons Attribution 4.0 International License, which permits use, sharing, adaptation, distribution and reproduction in any medium or format, as long as you give appropriate credit to the original author(s) and the source, provide a link to the Creative Commons licence, and indicate if changes were made. The images or other third party material in this article are included in the article's Creative Commons licence, unless indicated otherwise in a credit line to the material. If material is not included in the article's Creative Commons licence and your intended use is not permitted by statutory regulation or exceeds the permitted use, you will need to obtain permission directly from the copyright holder. To view a copy of this licence, visit http://creativecommons.org/licenses/by/4.0/. 
implant bone health [7]. Previously, it was shown that peri-implantitis did not give rise to an increase in osteocalcin, osteopontin, and osteonectin levels in PISF [4]. Hence, studies investigating the biomarkers that reflect the changes during peri-implant inflammation continue.

Antimicrobial peptides in the oral tissues are crucial participants of the equilibrium between healthy and diseased states $[8,9]$. Human cathelicidin antimicrobial peptide has a cathelin-like domain and a LL-37 part [8]. This antimicrobial peptide is expressed especially by neutrophils and epithelial cells $[10,11]$. Inactive human cathelicidin antimicrobial peptide is present in the neutrophil granules $[8,12]$. Following neutrophil stimulation, proteinase 3 activates this inactive peptide to produce cathelin-like domain and active LL-37 [12]. Proteinase 3 degrades extracellular matrix proteins, activates platelets, and induces the apoptosis [13-15]. Both LL-37 and proteinase 3 have effect on the nonoxidative killing of microorganisms [16, 17].

Gingival crevicular fluid (GCF) LL-37 and proteinase 3 levels were investigated in the presence of different periodontal diseases [18-24]. Researchers demonstrated that LL-37 antimicrobial peptide is related to periodontal inflammation [18, 21-24]. It was denoted that increased GCF LL-37 amounts in periodontal tissue destruction might be related to the innate immunity in inflammation of periodontal tissues [18]. Laugisch et al. showed that GCF proteinase 3 activity was the highest in gingivitis patients [20]. Our previous study revealed that proteinase 3 levels in GCF was higher in periodontally diseased patients compared to those in periodontally healthy, however similar between those of the periodontally diseased [21]. Probing depths might not be measured effectively because of the inappropriate prosthetic restorations. Additionally, it is known that the macro design of the implant and surface features could prevent appropriate probing and periodontal probe penetration into the pocket [25]. Since standard clinical measurements including pocket depth and bleeding upon probing are of limited diagnostic value for peri-implant diseases, additional prognostic criteria would be invaluable for detecting peri-implant diseases. Therefore, in this study, the hypothesis is that peri-implant tissue destruction caused by peri-implantitis might affect the LL37 and proteinase 3 amounts in peri-implant sulcus fluid (PISF). Accordingly, the aim is to evaluate LL-37 and proteinase 3 amounts in PISF in implant sites with and sites without peri-implantitis, in order to detect temporal changes regarding the progression of the disease.

\section{Materials and methods}

Patients having implants with peri-implantitis and without peri-implantitis simultaneously were identified to be included into study. A total of 16 patients who had both peri-implantitis and non-peri-implantitis sites were included into study. Each of the 16 patients had both study groups: peri-implantitis and non-peri-implantitis. Fortyfour implants with peri-implantitis and 34 implants without peri-implantitis from 16 patients were evaluated. Participants were selected among the individuals who admitted to the Periodontology Department, School of Dentistry, Ege University. All participants gave informed consents. Research protocol was approved by the Ege University Ethics Committee. Patients who had undertaken antibiotic in the past 3 months, who have infectious diseases, systemic diseases, and immunological disorders; women who were pregnant or who breastfeed; and smokers were excluded. Implants included in the study were minimum placed a year previously. They were also loaded for at least 6 months in a functional way.

\section{Intraoral measurements}

Intraoral measurements including pocket depth, attachment loss, bleeding upon probing, and plaque index were measured in the whole mouth to determine the periodontal condition of the patient $[26,27]$. Pocket depth was measured using a plastic periodontal probe. Modified sulcus bleeding index (MSBI), modified plaque index (MPI), and suppuration in the implants were evaluated [28]. Bone level around the implant was inspected by a peri-apical radiograph. A calibrated periodontist carried out all periodontal and peri-implant measurements.

\section{Study groups \\ Peri-implantitis group}

If an implant has bone loss more than $2 \mathrm{~mm}$ from the implant platform except for normal bone remodeling and pocket depth deeper than $4 \mathrm{~mm}$ and bleeding upon probing, it was diagnosed as peri-implantitis [29].

\section{Non-peri-implantitis group}

If an implant with or without bleeding upon probing has no radiographic bone loss except normal bone remodeling, it was diagnosed as non-peri-implantitis.

\section{Collecting PISF samples}

PISF sampling was performed 1 day after the clinical examination. PISF samples were obtained from implants with and without peri-implantitis on the same patient. Three or five PISF samples (samples with or without peri-implantitis) were obtained from each patient. A total of 78 samples (44 samples with peri-implantitis and 34 samples without peri-implantitis) were provided from 16 patients. PISF sampling was performed at interproximal surfaces of the implants as described before [4]. 


\section{Laboratory analysis}

Paper strips were incubated in $200 \mu \mathrm{l} 0.5 \%$ Tween solution with $0.1 \mathrm{M}$ phosphate-buffered saline for $15 \mathrm{~min}$. Then enzyme-linked immunosorbent kits ${ }^{1,2}$ were used for determining PISF LL-37 and proteinase 3 levels according to the directives of the kit. According to the kits, minimum detectable limits for LL-37 was $0.395 \mathrm{ng} / \mathrm{ml}$. Minimum detectable limits for proteinase 3 was 0.236 $\mathrm{ng} / \mathrm{ml}$. While making a calculation of the levels of the markers investigated, dilution rates were taken into consideration and results were presented as total amounts.

\section{Statistical analysis}

In order to achieve $95 \%$ power, at a medium effect size of 0.5 and with a significance level $\alpha=0.05$ using a twosided paired $t$ test, a minimum sample size was estimated as 54 (G*Power version 3.1.9.2, Franz, Universitat Kiel, Germany). Categorical data including MPI and MSBI were defined using observed frequencies and percentages. Continuous variables including pocket depth, PISF volume, and PISF LL-37 and proteinase 3 were given by the means and standard deviations with the statistical package ${ }^{3}$. Since the number of implants for each group and the number of implants for each person were unequal, the study design was unbalanced. Accordingly, we included random person effect and fixed effect for group in the model when comparing pocket depth, PISF volume, and PISF LL-37 and proteinase levels between two groups, and this model was analyzed by using SAS $9.3^{4}$. Group, jaw, and interaction effect between group and jaw were also evaluated for PISF LL-37 and proteinase 3 levels. Pearson analysis was applied for assessing the correlation between pocket depth and PISF volume and PISF LL-37 and proteinase 3 levels.

\section{Results}

\section{Demographics and intraoral data}

Demographic evaluation of 16 patients was performed. The mean age of the study participants was 54.06 years (42-66 years). Eight patients of the study participants were female. Four out of 16 patients were periodontally healthy, 4 of them had gingivitis, and 8 had chronic periodontitis [30]. Nineteen of the 44 peri-implantitis sites in 16 patients were located on the maxilla, and 25 were located on the mandibula. Nineteen of the 34 non-periimplantitis sites in 16 patients were on the maxilla, and 15 were on the mandibula. All participants were nonsmokers. The mean time between delivery of the

\footnotetext{
${ }^{1}$ Human LL-37 Enzyme-linked immunosorbent kit, Mybiosource

${ }^{2}$ Human Proteinase 3 Enzyme-linked immunosorbent kit, Mybiosource

${ }^{3}$ SPSS Inc., version 21.0, Chicago, IL, USA

${ }^{4}$ SAS Institute Inc., Cary, NC, USA, PROC MIXED
}

prosthesis and the appointment of examination were $8 \pm$ 2 years (mean \pm standard deviation).

Peri-implant data of the sampling sites is demonstrated in Table 1. Pocket depths of the implants with peri-implantitis was significantly increased in comparison to those without peri-implantitis $(p<0.0001)$. MSBI and MPI were significantly increased in implants with peri-implantitis in comparison to implants without periimplantitis $(p<0.05)$. PISF volume was increased in implants with peri-implantitis compared to implants without peri-implantitis $(p<0.05)$.

\section{PISF LL-37 and proteinase 3 levels}

Figure 1 shows PISF LL-37 and proteinase 3 levels in implant sites with and without peri-implantitis. No significant difference was observed in PISF LL-37 total amounts between implant sites with and without peri-implantitis $(p=0.585)$. There was no significant difference in PISF proteinase 3 total amounts between peri-implantitis sites and non-periimplantitis sites $(p=0.083)$. As to concentrations, there was a significant interaction in PISF LL-37 level between disease and jaw $(p<0.05)$. Similarly, significant interaction was observed in PISF proteinase 3 concentrations $(p<0.05)$. Correlations between PD and PISF LL-37 and proteinase 3 levels are presented in Table 2. There was no significant correlation between sampling sites' pocket depths and LL-37 total amounts $(p=0.506, r=0.077)$. Sampling sites' pocket depths and proteinase 3 total amounts were not correlated either $(p$ $=0.963, r=-0.005)$. However, there were significant correlations between pocket depth, PISF LL-37 concentration $(p=$ $0.000, r=0.461)$, and proteinase 3 concentrations $(p=0.000$, $r=0.478)$. As expected, pocket depth values of sampling sites were correlated with PISF volume $(p=0.000, r=0.496)$.

\section{Discussion}

It is stated that the assessment of proinflammatory activity in saliva and GCF could give information about the progress of the periodontal and peri-implant diseases [31-34]. Up to date, proinflammatory cytokines and antimicrobial peptides in GCF and saliva are investigated in various periodontal diseases $[18,24,31,35]$. Although proinflammatory cytokines, matrix metalloproteinases,

Table 1 Intraoral findings of sampling sites

\begin{tabular}{lll}
\hline $\begin{array}{l}\text { Intraoral parameters (mean } \pm \text { SD } \\
\text { or med (min-max)) }\end{array}$ & $\begin{array}{l}\text { Peri-implantitis } \\
(N=44)\end{array}$ & $\begin{array}{l}\text { Non-peri-implantitis } \\
(N=34)\end{array}$ \\
\hline Pocket depth & $6.5 \pm 1.4^{*}$ & $4 \pm 1.3$ \\
MPI & $2.5(2-3)^{*}$ & $2(0-3)$ \\
MSBI & $2(2-3)^{*}$ & $1(0-2)$ \\
PISF & $0.62(0.14-$ & $0.33(0.11-0.75)$ \\
& $0.99)^{*}$ & \\
\hline
\end{tabular}

MPI modified plaque index, MSBI modified sulcus bleeding index, PISF periimplant sulcus fluid

*Significant difference from non-periodontitis group 


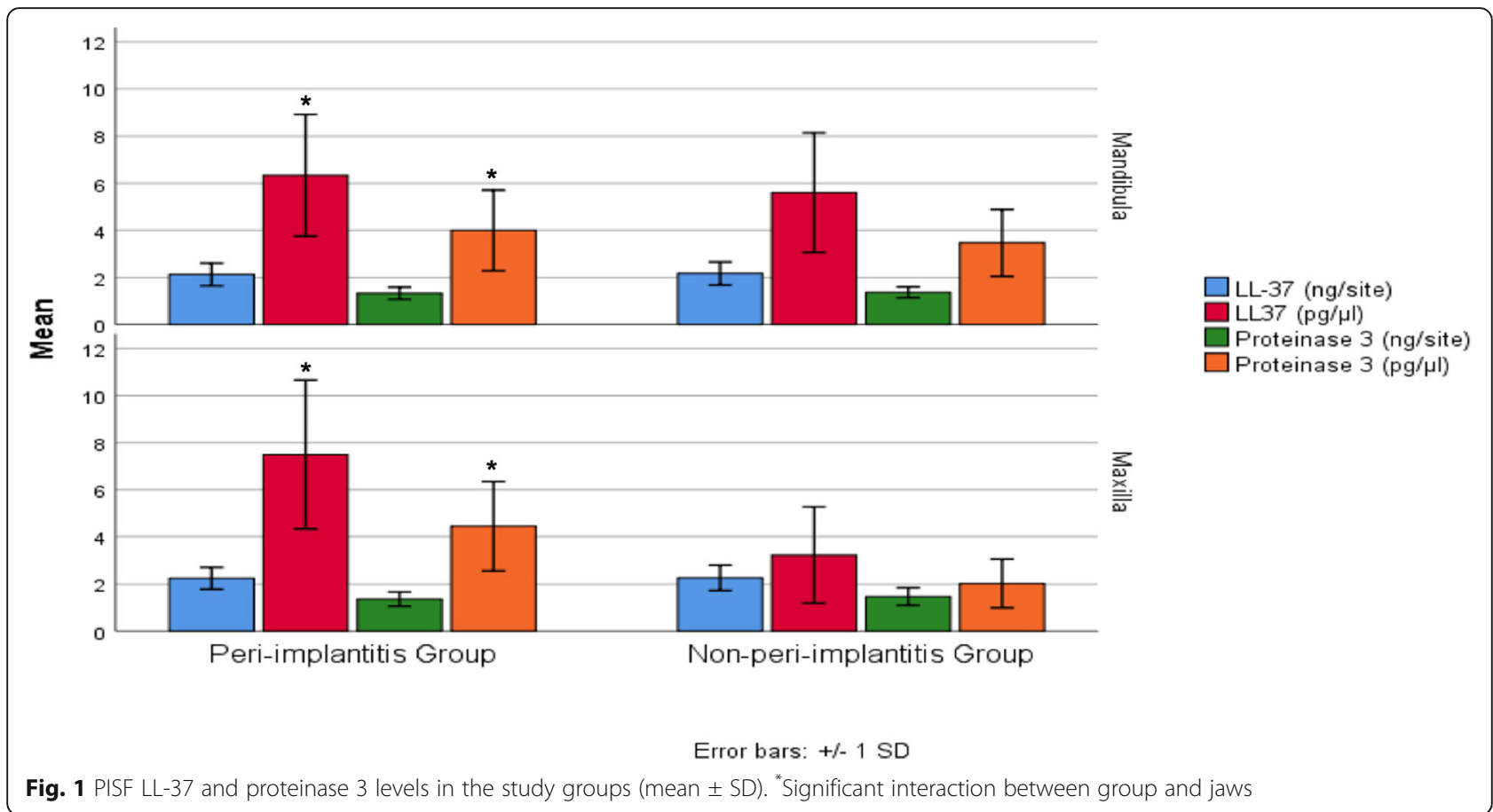

and proteolytic enzymes are well studied [21, 35-37], there is no study investigating antimicrobial peptides in peri-implant diseases. As far as we know, PISF LL-37 antimicrobial peptide and its activator-proteinase 3 levels were investigated in peri-implant diseases for the first time with this research. Our findings demonstrated no important changes in PISF LL-37 and proteinase 3 total amounts between implants with and without periimplantitis. Additionally, total amounts of PISF LL-37, proteinase 3, and pocket depth of sampling sites were not correlated.

It has been demonstrated that GCF reflects the inflammatory state that based on clinical status of the periodontal tissues [38]. In the literature, it has been stated that total amounts per standard sampling time is a better indicator of relative GCF constituent activity rather than GCF concentrations [39-41]. Besides, it has been suggested that PISF is similar to GCF as it reflects the inflammatory response [5]. Therefore, in the present study, PISF LL-37 and proteinase 3 levels were reported as total amounts per time of collection instead of reporting their concentration.

PISF volume of implants with peri-implantitis was increased in comparison to sites without peri-implantitis in the current study, and this result is in consistent with the other researches [42, 43]. Since PISF is an inflammatory exudate, one can reasonably expect to have elevated PISF volume in the presence of peri-implant tissue destruction. Epithelial cells and neutrophils express LL-37 antimicrobial peptide. In the presence of inflammation, blood vessels dilate and neutrophils migrate from the vessels to inflammation area. Studies demonstrated that GCF samples from periodontitis and gingivitis patients had increased levels of LL-37 [18, 21-24]. Our results showed that although PISF volume in implants with peri-implantitis was increased, PISF LL-37 levels in sites with and without peri-implantitis were similar. This could be a result of the compromised blood circulation around dental implants. The vascular supply to the zone of supra-alveolar connective tissue comes from the capillaries of the connective tissue under the epithelium, the vascular plexus near the junctional epithelium and the periodontal ligament [44]. Nevertheless, the vascular supply of peri-implant mucosa comes from the supraperiosteal vessels of the alveolar ridge only [44]. Periimplant mucosa is lack of the vascular supply of the periodontal ligament since there is no periodontal ligament between the implant and the surrounding bone.

Polymorphonuclear neutrophil granules have proteinase 3 which is expressed following its stimulation [44].

Table 2 Correlations between PD of sampling site and PISF LL-37 and proteinase 3 levels

\begin{tabular}{lllllll}
\hline Periodontal parameter & & LL-37 $(\mathrm{ng} / \mathrm{site})$ & $\mathrm{LL}-37(\mathrm{pg} / \mu \mathrm{l})$ & Proteinase 3 $(\mathrm{ng} / \mathrm{site})$ & Proteinase $3(\mathrm{pg} / \mu \mathrm{l})$ & $\mathrm{PISF}(\mu \mathrm{l})$ \\
\hline $\mathrm{PD}$ & $r$ & 0.077 & 0.461 & -0.005 & 0.478 & 0.496 \\
& $p$ & 0.506 & 0.000 & 0.963 & 0.000 & 0.000 \\
\hline
\end{tabular}


Several studies exhibited that GCF proteinase 3 levels were elevated in sites with periodontal tissue destruction in comparison to healthy periodontal tissues [19-21]. Similarly, in our previous study, it was presented that proteinase 3 levels in GCF were increased in patients with periodontal tissue loss in comparison to healthy controls, but similar between periodontitis and gingivitis subjects [21]. In this current study, proteinase 3 levels in PISF were similar between peri-implantitis and nonperi-implantitis sites. Reduced blood circulation of the supra-alveolar connective tissue of dental implants compared to natural dentition might lead to a relative reduction in the number of neutrophils migrating from periimplant connective tissue to peri-implant sulcus. This in turn might be the reason for similar proteinase 3 levels in PISF between the groups. Additionally, the presence of sites with peri-implant mucositis as well as healthy peri-implant tissues in non-peri-implantitis group might contribute to the above mentioned finding in the present study. Therefore, studies investigating PISF proteinase 3 levels in peri-implant healthy, peri-implant mucositis, and peri-implantitis might yield more information regarding the pathogenesis of peri-implant diseases. Both proteinase 3 and LL-37 levels in PISF were similar in study groups in this current study. This finding is not unexpected considering the fact that proteinase 3 is the enzyme cleaving hCAP18 to mature LL-37 peptide, and both proteinase 3 and LL-37 are mainly expressed by neutrophils. Therefore, similar levels of these two molecules in PISF is to be anticipated.

There are some limitations in the present study. PISF samples were obtained from implants with prosthetic restorations that make the sample collection difficult. Second, although the control group in this current study comprised of implants without peri-implantitis, some of these implants had peri-implant mucositis. Since the purpose of this current study was to evaluate PISF proteinase 3 and LL-37 levels in the presence of periimplant tissue destruction, implants with peri-implant mucositis were also included in the control group. Although implants having peri-implant mucositis did not have peri-implant tissue destruction, they had mucosal inflammation. Therefore, studies evaluating the influence of mucosal inflammation on the PISF proteinase 3 and LL-37 levels would provide detailed information regarding the levels of these molecules during the inflammatory process of peri-implant diseases.

\section{Conclusion}

Peri-implantitis might increase PISF volume in response to peri-implant bone loss. However, peri-implant tissue destruction caused by peri-implantitis does not seem to affect PISF LL-37 and proteinase 3 levels. Within the limits of this current study, we concluded that PISF LL-
37 and proteinase 3 levels could not be used as prognostic criteria for detecting peri-implant bone loss.

\section{Abbreviations \\ GCF: Gingival crevicular fluid; PISF: Peri-implant sulcus fluid; MSBI: Modified sulcus bleeding index; MPI: Modified plaque index}

\section{Acknowledgments}

We would like to thank Semiha Ozgul from the Department of Biostatistics and Medical Informatics, School of Medicine, Ege University, for the statistical analysis.

\section{Authors' contributions}

OT Conceptualization, methodology, project administration, writing of the original draft. CE Investigation, project administration, review, and editing. HA Formal analysis. All authors read and approved the final version of the manuscript.

\section{Funding}

This study was supported by Ege University Research Foundation (2017-DIS010).

\section{Availability of data and materials}

The datasets used and/or analyzed during the current study are available from the corresponding author on reasonable request.

\section{Ethics approval and consent to participate}

The research protocol was approved by the Ege University Ethics Committee. All participants gave informed consent.

\section{Consent for publication}

N/A

\section{Competing interests}

Oya Turkoglu, Candan Efeoglu, and Harika Atmaca declare that they have no competing interests.

\section{Author details}

'Department of Periodontology, School of Dentistry, Ege University, Bornova, 35100 Izmir, Turkey. ${ }^{2}$ Department of Oral Surgery, School of Dentistry, Ege University, Izmir, Turkey. ${ }^{3}$ Department of Biology, Celal Bayar University, Manisa, Turkey.

Received: 16 December 2019 Accepted: 18 June 2020

Published online: 04 August 2020

\section{References}

1. Zitzmann NU, Berglundh T. Definition and prevalence of peri-implant disease. J Clin Periodontol. 2008;35:286-91.

2. Bhardwaj S, Prabhuji ML. Comparative volumetric and clinical evaluation of peri-implant sulcular fluid and gingival crevicular fluid. J Periodontal Implant Sci. 2013;43:233-42.

3. Tözüm TF, Akman AC, Yamalik N, et al. Analysis of the inflammatory process around endosseous dental implants and natural teeth: myeloperoxidase level and nitric oxide metabolism. Int J Oral Maxillofac Implants. 2007;22: 969-79.

4. Cakal TO, Efeoglu C, Bozkurt E. The evaluation of peri-implant sulcus fluid osteocalcin, osteopontin, and osteonectin levels in peri-implant diseases. J Periodontol. 2018;89:418-23.

5. Thierbach R, Maier K, Sorsa T, Mäntylä P. Peri-implant sulcus fluid (PISF) matrix metalloproteinase (MMP)-8 levels in peri-implantitis. J Clin Diagn Res. 2016;10:ZC34-8

6. Ata-Ali J, Flichy-Fernández AJ, Alegre-Domingo T, Ata-Ali F, Palacio J, Peñarrocha-Diago M. Clinical, microbiological, and immunological aspects of healthy versus peri-implantitis tissue in full arch reconstruction patients: a prospective cross-sectional study. BMC Oral Health. 2015;1:15-43.

7. Acipinar S, Karsiyaka Hendek M, Olgun E, Kisa U. Evaluation of FGF-23 and 25(OH)D 3 levels in peri-implant sulcus fluid in peri-implant health and diseases. Clin Implant Dent Relat Res. 2019;21:1106-12.

8. Bals R, Wilson JM. Cathelicidins-a family of multifunctional antimicrobial peptides. Cell Mol Life Sci: CMLS. 2003;60:711-20. 
9. Dale BA, Fredericks LP. Antimicrobial peptides in the oral environment: expression and function in health and disease. Curr Issues Mol Biol. 2005;7: 119-33.

10. Dale BA, Kimball JR, Krisanaprakornkit S, Roberts F, Robinovitch M, O'Neal R, et al. Localized antimicrobial peptide expression in human gingiva. J Periodontal Res. 2001;36:285-94.

11. Turkoglu O, Kandiloglu G, Berdeli A, Emingil G, Atilla G. Antimicrobial peptide hCAP-18/LL-37 protein and mRNA expressions in different periodontal diseases. Oral Dis. 2011;17:60-7.

12. Sorensen $O E$, Follin P, Johnsen AH, Calafat J, Tjabringa GS, Hiemstra PS, et al. Human cathelicidin, hCAP18, is processed to the antimicrobial peptide LL-37 by extracellular cleavage with proteinase 3. Blood 2001;97:3951-3959.

13. Rao NV, Wehner NG, Marshall BC, Gray WR, Gray BH, Hoidal RJ. Characterization of proteinase-3 (PR3), a neutrophil serine proteinase: structural and functional properties. J Biol Chem. 1991;15:9540-8.

14. Renesto P, Halbwachs-Mecarelli L, Nusbaum P, Lesavre P, Chignard M. Proteinase 3: a neutrophil proteinase with activity on platelets. J Immunol. 1994;9:4612-7

15. Yang JJ, Kettriz R, Falk RJ, Jennette JC, Gaido ML. Apoptosis of endothelial cells induced by the neutrophil serine proteases proteinase 3 and elastase. Am J Pathol. 1996:5:1617-26.

16. Korkmaz B, Moreau T, Gauthier F. Neutrophil elastase, proteinase 3 and cathepsin G: physicochemical properties, activity and physiopathological functions. Biochimie. 2008;2:227-42.

17. Pham CTN. Neutrophil serine proteases fine-tune the inflammatory response. Int J Biochem Cell Biol. 2008;6(7):1317-33.

18. Turkoglu O, Emingil G, Kutukculer N, Atilla G. Gingival crevicular fluid levels of cathelicidin LL-37 and interleukin-18 in patients with chronic periodontitis. J Periodontol. 2009;80:969-76.

19. Komine $K$, Kuroishi T, Ozawa A, Komine $Y$, Minami T, Shimauchi $H$, et al. Cleaved inflammatory lactoferrin peptides in parotid saliva of periodontitis patients. Mol Immunol. 2007:44:1498-508.

20. Laugisch O, Schacht M, Guentsch A, Kantyka T, Sroka A, Stennicke HR, et al. Periodontal pathogens affect the level of protease inhibitors in gingival crevicular fluid. Mol Oral Microbiol. 2012;27:45-56.

21. Türkoğlu O, Azarsız E, Emingil G, Kütükçüler N, Atilla G. Are proteinase 3 and cathepsin $C$ enzymes related to pathogenesis of periodontitis? Biomed Res Int. 2014;2014:420830.

22. Puklo M, Guentsch A, Hiemstra PS, Eick S, Potempa J. Analysis of neutrophilderived antimicrobial peptides in gingival crevicular fluid suggests importance of cathelicidin LL-37 in the innate immune response against periodontogenic bacteria. Oral Microbiol Immunol. 2008;23:328-35.

23. Türkoğlu O, Eren G, Emingil G, Azarsız E, Kutukculer N, Atilla G. Does smoking affect gingival crevicular fluid LL-37 levels following non-surgical periodontal treatment in chronic periodontitis? Arch Oral Biol. 2016;61:98-105.

24. Hosokawa I, Hosokawa Y, Komatsuzawa H, Goncalves RB, Karimbux N, Napimoga $\mathrm{MH}$, et al. Innate immune peptide LL37 displays distinct expression pattern from beta-defensins in inflamed gingival tissue. Clin Exp Immunol. 2006;146:218-25.

25. Mombelli A, Lang NP. Clinical parameters for the evaluation of dental implants. Periodontol 2000. 1994:4:81-6.

26. Muhlemann HR, Son S. Gingival sulcus bleeding - a leading symptom in initial gingivitis. Helv Odontol Acta. 1971:15:107-13.

27. Ainamo J, Bay I. Problems and proposals for recording gingivitis and plaque. Int Dent J. 1975:25:229-35.

28. Mombelli A, van Oosten MA, Schurch E Jr, Land NP. The micro-biota associated with successful or failing osseointegrated titanium implants. Oral Microbiol Immunol. 1987;2:145-51.

29. Dauber DM, Weinstein BF, Bordin S, Leroux BG, Flemming TF. Prevalence and predictive factors for peri-implant disease and implant failure: a crosssectional analysis. J Periodontol. 2015:86:337-47.

30. Armitage GC. Development of a classification system for periodontal diseases and conditions. Ann Periodontol. 1999;4:1-6.

31. Belstrom D, Damgaard C, Kononen E, Gürsoy M, Holmstrup P, Gürsoy UK, et al. Salivary cytokine levels in early gingival inflammation. J Oral Microbiol. 2017;9:1364101.

32. Javed F, Al-Hezaimi K, Salameh Z, Almas K, Romanos GE. Proinflammatory cytokines in the crevicular fluid of patients with peri-implantitis. Cytokine. 2011;53:8-12.

33. Kivela-Rajamaki M, Maisi $P$, Srinivas $R$, Tervahartiala $T$, Teronen $O$, Husa, et al. Levels and molecular forms of MMP-7 (matrilysin-1) and MMP-8 (collagenase-2) in diseased human peri-implant sulcular fluid. J Periodontal Res. 2003;38:583-90.

34. Romano F, Bongiovanni L, Bianco L, Di Scipio F, Yang Z, Sprio A, et al. Biomarker levels in gingival crevicular fluid of generalized aggressive periodontitis patients after non-surgical periodontal treatment. Clin Oral Investig. 2018;22:1083-92.

35. Aboyoussef H, Carter C, Jandinski JJ, Panagakos FS. Detection of prostaglandin E2 and matrix metalloproteinases in implant crevicular fluid. Int J Oral Maxillofac Implants. 1998;13:689-96.

36. Kao RT, Curtis DA, Richards DW, Preble J. Increased interleukin-1 beta in the crevicular fluid of diseased implants. Int J Oral Maxillofac Implants. 1995;10: 696-701.

37. Recker EN, Avila-Ortiz G, Fischer CL, Pagan-Rivera K, Brogden KA, Dawson DV, et al. A cross-sectional assessment of biomarker levels around implants versus natural teeth in periodontal maintenance patients. J Periodontol. 2015;86:264-72

38. Jin L, Soder B, Corbet EF. Interleukin-8 and granulocyte elastase in gingival crevicular fluid in relation to periodontopathogens in untreated adult periodontitis. Journal of Periodontology. 2000;71:929-39.

39. Lamster IB, Hartley LJ, Oshrain RL, Gordon JM. Evaluation and modification of spectrophotometric procedures for analysis of lactate dehydrogenase, beta-glucuronidase and arylsulphatase in human gingival crevicular fluid collected with filter-paper strips. Archives of Oral Biology. 1985;30:235-42.

40. Lamster IB, Oshrain RL, Gordon JM. Enzyme activity in human gingival crevicular fluid: considerations in data reporting based on analysis of individual crevicular sites. Journal of Clinical Periodontology. 1986:13:799-804.

41. Tsai CC, Ho YP, Chen CC. Levels of interleukin-1 beta and interleukin-8 in gingival crevicular fluids in adult periodontitis. Journal of Periodontology. 1995;66:852-9.

42. Tümer C, Aksoy Y, Güncü GN, Nohutcu RM, Kilinc K, Tözüm TF. Possible impact of inflammatory status on C-telopeptide pyridinoline cross-links of type I collagen and osteocalcin levels around oral implants with periimplantitis: a controlled clinical trial. J Oral Rehabil. 2008;35:934-9.

43. Murata M, Tatsumi J, Kato Y, et al. Osteocalcin, deoxypyridino line and interleukin-1 beta in peri-implant crevicular fluid of patients with periimplantitis. Clin Oral Implants Res. 2002;13:637-43.

44. Lindhe J, Wennstrom JL, Berglundh T. In: Lindhe J, Lang NP, Karring T, editors. The mucosa at teeth and implants. Oxford Blackwell Publishing Ltd: Clinical Periodontology and Implant Dentistry; 2008. p. 69-85.

\section{Publisher's Note}

Springer Nature remains neutral with regard to jurisdictional claims in published maps and institutional affiliations.

\section{Submit your manuscript to a SpringerOpen ${ }^{\circ}$ journal and benefit from:}

- Convenient online submission

- Rigorous peer review

- Open access: articles freely available online

High visibility within the field

- Retaining the copyright to your article

Submit your next manuscript at $>$ springeropen.com 